УДК 78.01+78.03/782
DOI https://doi.org/10.31723/2524-0447-2020-30-2-14

Галина Николаевна Дубровская

ORCID: 0000-0002-0248-3822

кандидат искусствоведения,

доцент кафедры общего и специализированного фортепиано

Одесской национальной музыкальной академии

имени А. В. Неждановой

dubrovskajagn@gmail.com

\title{
«ПАМЯТЬ КУЛЬТУРЫ» В РУССКОЙ МУЗЫКЕ РУБЕЖА ХIX-XX ВЕКОВ
}

\begin{abstract}
Актуальность темы. В связи с новыми общественно-политическими и историко-культурологическими реалиями, идея сохранения «памяти культуры» (термин академика Д. Лихачева) становится особенно актуальной. В советский период некоторые факты и события, биографии выдающихся деятелей культуры, названия и смысл произведений искусства нередко трактовались в искаженном свете. При всем негативе, подобная трактовка иногда спасала от забвения имена многих великих людей и их творения. Поэтому столь важна функция искусства, запечатлевающего эти факты, события в словах, красках, звуках, бережно сохраняющего их и передающего историческую правду потомкам. К культурной памяти относится и русский язык, как носитель информации, поскольку на этом языке, с одной стороны, написаны тексты опер, камерно-вокальных произведений, с другой - исследования выдающихся философов и музыковедов ХХ столетия: Д. Лихачева, С. Авериниева, А. Лосева, П. Флоренского, Б. Асафьева, Е. Назайкинского, В. Медушевского, Е. Ручьевской и многих других. Цель данной статьи - выявление аспектов, связанных с идеей «памяти культуры» в русской музыке рубежка XIX-XX веков и их проекции на музыковедение XX-ХХІ столетий. Методология. Для достижения этой иели используются методы историко-культурологического, музыковедческого и жанрово-стилистического анализа светских и духовных произведений русских композиторов рубежа ХІХ-ХХ веков. Научная новизна. Историко-культурологический и теоретический анализ произведений русских композиторов рассматриваемого периода с позиций исторической «памяти культуры» является одним из недостаточно исследованных разделов отечественного музыкознания. Выводы статьи позволяют говорить о взаимовлиянии светской профессиональной и духовной музыки на рубеже ХІХ-ХХ веков в контексте «памяти культуры». Анализ произведений с предло-
\end{abstract}

(C) Дубровская Г. Н., 2020 
женной точки зрения требует пересмотра некоторых положений в

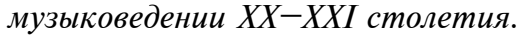

Ключевые слова: древние роспевы, культура традиции, «память культуры», панихидные символы, литургические интонации.

Dubrovska Halyna Mykolaivna, Ph.D. in the History of Art, Assistant Professor at the Department of General and Specialize Piano of the Odessa National A. V. Nezdanova Academy of Music

The "memory of culture" in Russian music of boundary of XIX$X X$ centuries

Actuality of theme. In connection with new socio-political and historiccultural realities idea of keeping consists of keeping the "memory of culture" (thermion by D. Likhachev) in Russian music of boundary of XIX$X X$ centuries begin especially actual. In soviet period some facts and events, biographies of outstanding artists, titles and meaning in works of art not infrequently interpreted in a distorted light. With everything negative, this interpretation sometimes saved from oblivion the names of many great peoples and their creations. That's why so mean a function of art, which imprinting their facts, events in words, colours, sounds, carefully preserving them and transmitting historic truth to descendants. To memory of culture treating a Russian language as carrier of information so far as on this language, from one side, are written the texts of operas, chamber-vocal works, from other side - researchings of outstanding philosopher and musicologist of XX century: D. Likhachev, A. Losev, P. Florensky, B. Asafiev, E. Nazaikin, $V$. Medushevsky, E. Ruchevskaja and many other.

The purpose of this article is the revelation of aspects, which connecting with the "memory of culture" in Russian music of boundary of $X I X-X X$ centuries. The methodology. For achievement of this purpose we use the methods of historical-cultural, musicological and genre-style analysis of secular and spiritual works of Russian composer's boundary of XIX-XX centuries. Scientific novelty. Historical-culture and theoretical analysis of secular of works of Russian composers of boundary of XIX-XX centuries in attitude of problematic of "memory of culture" is one of insufficient researching section of native musicologist. Conclusions of article permit to say about mutual influence of secular professional and spiritual aspects on boundary of $X I X-X X$ centuries in context of the "memory of culture". Analysis of works with suggesting point of view is demanding reconsidering some position in musicology of $X X$ XXI centuries.

Key words: the ancient singings, culture of tradition, the memory of culture, symbols of office for the dead, intonations of liturgics.

Дубровська Галина Миколаївна, кандидат мистецтвознавства, доцент кафедри загального та спеціалізованого фортепіано Одеської національної музичної академії імені А. В. Нежданової

"Пам'ять культури» у російській музиці на межі XIX-XX століть

Актуальність теми. $У$ зв'язку з новими громадсько-політичними та історично-культурологічними реаліями ідея збереження «пам'яті 
культури» (термін академіка Д. Ліхачова) у російській музиці на межі ХІХ-XX століть стає особливо актуальною. У радянський період деякі факти та події, біографії видатних діячів культури, назви та сенс творів мистецтва нерідко трактувалися у спотвореному світі. Попри весь негатив, подібне трактування іноді рятувало від забуття імена багатьох великих людей та їх творіння. Тому так важлива функція мистецтва, яке запам'ятовує иі факти, події в словах, фарбах, звуках, обережно зберігаючи їх та передаючи історичну правду нащадкам. До культурної пам'яті належить і російська мова, як носій інформації, оскільки на цій мові, з одного боку, написані тексти опер, камерно-вокальних творів, з іншого - дослідження видатних філософів та музикознавців ХХ століття: Д. Лихачова, С. Аверінцева, А. Лосєва, П. Флоренського, Б. Асаф'єва, Е. Назайкнського, В. Медушевського, E. Руч'євської та багатьох інших. Метою статті є виявлення аспектів, пов'язаних з ідеєю «пам'яті культури» (термін Д. Ліхачова) у російській музиці кіния ХІХ початку XX століть. Методологія. Для досягнення мети використовуються методи історійко-культурологічного, музикознавського та жсанрово-стилістичного аналізу світських та духовних творів російських композиторів на межі ХІХ-ХХ століть. Наукова новизна. Історико-культурологічний та теоретичний аналіз творів російських композиторів на межі XIX-XX століть з позицій історичної «пам'яті культури» $\epsilon$ однією з недостатньо досліджених розділів вітчизняного музикознавства. Висновки статті дозволяють говорити про взаємовплив у контексті «пам'яті культури» світської професійної та духовної музики на межсі ХІХ-ХХ століть. Аналіз творів з иієї точки зору потребує перегляду деяких положень у музикознавстві ХХ-ХХІ століть.

Ключові слова: старовинні розспіви, «культура традиції, «пам'ять культури», панахидні символи, літургічні інтонації.

Актуальность темы исследования. В периоды истории, особенно связанные со сменой общественно-политических формаций, пересматриваются и переоцениваются многие явления прошлого, в том числе в области искусства и культуры, корректируются некоторые устоявшиеся, но не отвечающие современным требованиям, критические и теоретические взгляды. Но и в новых исторических реалиях остаются традиции и «генетическая память» культуры. Как показала история, после октябрьского переворота попытка «старый мир разрушить до основанья, а затем...» потерпела неудачу. Новая, казалось, страна, сменив общественный строй, унаследовала традиции предшествовавшей, ведь деятели культуры были «родом оттуда», из бывшего дворянства и старой русской интеллигенции, которые невольно передавали, впитанные с детства привычки и образ мышления новым поколениям 
молодой, уже советской интеллигенции. Кто-то искренне поверил в перспективу «светлого будущего», кому-то надо было приспособиться к новому и неизбежному, компромиссно рассматривая очевидные факты под «нужным» углом зрения. Бесконечно преданные Родине, попав в совершенно иные условия, они должны были принять эти условия, чтобы выжить, либо покинуть Родину, что стало для большинства личной трагедией.

Цель статьи - определение понятия «память культуры» и исследование этого феномена в русской музыке рубежа XIX$\mathrm{XX}$ веков.

Изложение основного материала. Одной из основных проблем и зол стал атеизм. Ведь весь уклад жизни населения царской России, от крестьян и низших, бедных слоев до интеллигенции, дворян и представителей царской фамилии был связан с Православием. Русский человек, родившись, принимал Святое Крешение, причащался, венчался, крестил своих детей и был отпет по православному обряду. Это было заложено в его генетической памяти. Такую же память приобретала и культура, им взращиваемая, и искусство. Человек осознавал: «Вселенная - книга, написанная перстом Божиим... Ощущение значительности и величия мира лежало в основе литературы...» [3, с. 8], и это передавалось в устной традиции: в сказаниях, былинах, сказках, народных песнях, религиозных обрядах. Но многое было запечатлено в произведениях классического искусства, которое имело очень давние истоки. По словам выдающегося культуролога XX в. акад. Д.С. Лихачева, Древняя Русь, «в традиционном смысле этого слова, обнимающем страну и ее историю с X по XVII в., обладала великой культурой <..> прославлена во всем мире своею живописью и архитектурой. Но она замечательна не только этими «немыми» искусствами, позволившими некоторым западным ученым называть культуру Древней Руси культурой великого молчания <...> начинает происходить открытие древнерусской музыки и медленнее - гораздо более трудного для понимания искусства - искусства слова, литературы <...> Русская литература существует не с XVIII века. Она родилась не в Петербурге и не в «Петербургском периоде» русской истории» [3, с. 3-4]. При этом справедливо подчеркивается общность народа, создававшего эту культуру: «...первые триста лет были общим началом для литератур трех великих восточнославян- 
ских народностей: русской, украинской и белорусской <..> и впоследствии они тесно связаны между собой едиными литературными традициями, живым общением, общими писателями и многими общими произведениями» [3, с. 4], - мысль, как нельзя более актуальная в сегодняшнее время, когда уже после распада СССР и образования независимых государств меняется отношение к предшествующей истории и культуре, согласно уже новой идеологии. Понятно, что жизнь не стоит на месте, появляется много нового, ценного, интересного, но «генетическая память» человечества, народа, отдельной личности и культуры в целом должна оставаться.

Издавна жизнь русского человека была во многом общественна, соборна. В древней литературе авторское начало «было приглушено. В ней не было ни Шескпира, ни Данте. Это хор, в котором совсем нет или очень мало солистов и в основном господствует унисон» [3, с. 6]; и в древнерусской, особенно в духовной музыке оно также было подчинено коллективному началу: роспевы сочинялись либо одним талантливым человеком, либо несколькими единомышленниками, но в любом случае, исполнялись совместно - ансамблем, хором. Были роспевы разных областей, регионов: киевские, почаевские, соловецкие, московские, валаамские..., но затем распространялись, обменивались между собой, объединял их универсальный на тот период церковнославянский язык. Это же запечатлелось в генетической памяти народа, переходя сквозь столетия до наших дней, требуя уравновешивания проблемы национальной идентичности каждого народа и общности, единства, соборности, в которой кормчим, безусловно, является религия. Соборность предполагалась и в иконописи. О. Павел Флоренский писал: «Икона, даже первообразная, никогда не мыслилась произведением уединенного творчества, она существенно принадлежит соборному делу Церкви. И даже если по тем или иным причинам икона от начала до конца написана одним мастером, то какое-то идеальное соучастие в ее написании других мастеров подразумевалось $<\ldots>$ Ведь отсутствие соучастников требуется ради единства индивидуальной манеры, а в иконе - главное дело в незамутненности соборно передаваемой истины» [9, с. 159-160], а «обезличенность» авторства составляла мудрость и глубину, предполагая смиренность, невозвеличивание, не гордыню. 
Русская культура, как уже говорилось, основана на традиции, «памяти культуры» (по Д. Лихачеву), что на рубеже XIX$\mathrm{XX}$ веков повлияло на создание определенного стиля и характера произведений искусства, как связанных с религиозной тематикой светских, так и духовных. «Отдавая должное гармоническому пению и в техническом отношении высокоразвитому в России $<\ldots>$ его изменившиеся направления всегда зависели от веяний своего времени» (курсив мой), - писал С. Смоленский. Это требовало нового отношения к качеству репертуара, как в практике богослужения, так и духовных концертов: «...едва блеснула надежда быть услышанным в дивном исполнении Синодального хора, как сейчас же откликнулся целый ряд авторов, почти впервые начавших писать для церковного хора, как, например, Кастальский, Гречанинов, Ипполитов-Иванов, Ильинский, Рахманинов, Чесноков и многие другие $<\ldots>$ И очень важно, что появилась такая музыка, ибо так воспитывается слух и разумение масс с помощью хорошего исполнения хороших сочинений» [7, с. 469]. При этом одним из главных элементов новой русской церковной музыки становится «широкое использование древних роспевов в качестве не столько cantus firmus'a для гармонизации, сколько в качестве высшего критерия стиля, критерия (курсив мой), властно определяющего и мелодический материал, и формы многоголосного изложения его». Уже Римский-Корсаков близко подошел в своих переложениях к попытке такого «своеобразного понимания мелодий древних роспевов и дал элементарную форму их соответственной обработки...». В сочинениях современных композиторов материал древних роспевов стал «более живым, гибким», получил необыкновенную выразительность и красоту. Ему предоставили свободное развитие в формах, «более отвечающих его мелодическому складу, и древний роспев здесь вырос скорее до значения музыкальной темы (курсив мой), подлежащий именно тематическому развитию, что и создало совершенно иной стиль..., настала пора настоящей художественной реставрации (курсив мой) древних напевов, чем и являются лучшие и наиболее крупные произведения виднейших авторов этого направления (главным образом произведения А.Д. Кастальского, «Всенощное бдение» С.В. Рахманинова и др.)» с возможностью «стильной обработки подлинных мелодий» и вместе с тем «создания новых мелодий в том же самом стиле». [7, с. 663-664]. 
Русская культура связана с обрядовостью (в том числе поминальной), отсюда - использование соответствующей символики в светской музыке, и введение «панихидных» символов: «Со святыми упокой», «Вечная память», «Святый Боже» (по панихидному напеву) и другие, играющих основную роль в «опознании», «дешифровке»: С. Танеев «Иоанн Дамаскин», «По прочтении псалма»; М. Черепнин «Хождение по мукам Богородицы»; П. Чайковский «Покаянная молитва про Русь»; пример «поминальной колокольности» в операх - три «погребальных» удара колокола в завершении арии Ленского «Куда, куда» в «Евгении Онегине»; тропарь «Благословен еси, Господи» из «Всенощной» в третьей части «Симфонических Танцев» С. Рахманинова - опознавательный знак идей автора. В области поминально-литургической символики неоценима роль А. Кастальского, создавшего аналогичные С. Танееву произведения: «Пещное действо», «Братское поминовение» и «Вечная память героям». В «Основах народного многоголосия» он выделил характерные черты мелодики, отразившие характерные особенности его авторского стиля - синтез знаменного роспева с приемами русской народной подголосочной полифонии, среди которых: «воздушная септима» (то есть скачок на септиму с заполнением); скачки на широкие интервалы; хроматизмы; в области гармонии - «терпкие» звучания: квартовые септаккорды, их обращений - квинтовых нонаккордов, а также кварт с «пристройкой большой секунды сверху или снизу».

В советский период некоторые факты и события, биографии выдающихся деятелей культуры, названия и смысл произведений искусства нередко трактовались в искаженном свете, подстраиваясь под определенные идеологические установки. При всем негативе, подобная трактовка иногда спасала от забвения имена многих великих людей и их творения (подобно жертве качества в шахматной партии). В советских изданиях религиозная проблематика в русском искусстве представлялась данью историческому прошлому, либо обращением к мифологическим сюжетам. В монографии «П.И. Чайковский» [1] (1967 г.) А. Альшванг религиозно-философский текст романса ор. 16 «Новогреческая песнь» (на слова А. Майкова): «В темном аде, под землей, тени грешные томятся... Жены плачут, стонут: есть ли небо голубое? Есть ли свет еще там белый? Есть ли в свете Церкви Божьи 
И иконы золотые?», трактует как «вполне оригинальное музыкальное воплощение поэтического мифа об адских муках» (курсив мой) [2, с. 368]. Чайковский же искренне веровал, записав по окончании Шестой симфонии: «Господи, благодарю тебя!» [2, с. 817]. По мнению В. Брянцевой «Симфонические Танцы» С. Рахманинова, подобно «Фантастической симфонии Берлиоза или «Манфреду» Чайковского, заканчиваются картиной «шабаша нечистой силы» [3, с. 589], а цитирование в третей их части тропаря «Благословен еси, Господи» из «Всенощной» она объясняет сохранением преданности шестидесятилетнего музыканта «высоким идеалам, усвоенным на родной земле, и опорой на великую мощь народно-песенного начала, «хорового» в широком смысле слова» (курсив наш) [3, с. 593]. В корне менялся смысл и причастного концерта «В молитвах неусыпающую Богородицу» - «В могилах неизвестных героев». В постсоветский период можно открыто сказать о религиозных взглядах композиторов рубежа XIX-XX веков, писавших как светские, так и духовные произведения, отчего переплетались интонации в обеих сферах, например, в операх Н. Римского-Корсакова: «Псковитянка», «Сказание о Невидимом граде Китеже» (имитация оркестром «Фаворского света»), «Царская невеста» (ход на восходящую сексту е-с и «спад» в ариозо Любаши «Ах, до чего я дожила, Григорий!» «сокрушенный», как «Помилуй»).

Но если в вокальных жанрах зрима взаимосвязь музыки и текста, то в инструментальных - символична. Например, поминальный символ «Со святыми упокой», возникший из «единства со словом», переходя в светскую музыку, «уже как автономная музыкальная тема - не теряет смысловой связи со словесным первоисточником: слово «просвечивает» сквозь мелодический материал» [6, с. 51], как и темы «Со святыми упокой» - во вступлении к кантате С. Танеева «Иоанн Дамаскин». Текст 118 псалма «Благословен еси, Господи» «просвечивает» в «Симфонических танцах» С. Рахманинова, в «Бегстве Врангеля» Г. Свиридова и др., в интонационных очертаниях второй части Пятой симфонии П. Чайковского (аскетизм подчеркнут унисоном басовых инструментов, имитирующим пение мужских монастырских хоров).

В жанрах, связанных со словом, где, подобно образу, «просвечивающему» сквозь символ (по Аверинцеву), образ становится «прозрачным», «узнавание» происходит быстрее и 
легче; в инструментальной музыке ему способствуют штрихи и исполнительская артикуляция. И конечно, помощь в этом «опознании» оказывает своего рода «шифр», символика, в которую автор бережно вкладывает свои намерения, и расшифровка дается знающим и чувствующим законы музыкальной стилистики, в данном случае православно-церковных роспевов. Такими законами, по Е. Ручьевской, являются: 1) изложение музыкального материала для хора, причем без сопровождения, a capella; 2) ориентированность его на специфику текстов, с их синтаксической и ритмической структурой; 3) связь жанра духовных песнопений с традицией, с многовековой практикой церковной жизни. Отсюда - «включение в песнопения традиционных, стереотипных оборотов, ритмических и мелодических формул-кадансов, специфических гармонических и мелодических ладовых оборотов».

Ocобо выделяется в этом плане этюд-картина c-moll С. Рахманинова (из опубликованных посмертно), почти вся вторая до-мажорная часть которого - «расширенная» кульминация (две страницы, 28 тактов выдержаны в динамических градациях оттенка рiano: от рррр до рр на протяжении девяти тактов при широком охвате регистров от субконтроктавы до g третьей октавы) с «заполнением» C-durным арпеджиато и с постепенно «возносящимися» фигурациями, на вершинах которых возникает вторая тема ррр. Это как бы «тихая» кульминация этюда и в формообразующем, и в психологическом плане. Приемы задержания, хроматического восходящего и нисходящего «скольжения», переченья сочетания в одном аккорде до диеза и до бекара (тт. 20-21), «плывущей» над фоном мелодии (прием, предугадывающий «высотную» широкоформатную киносъемку) создают впечатление неземного восхождения - воспарения, прорыва в иную реальность («серафическая просветленность», по определению И. Сухомлинова); один из самых трогательных эпизодов произведений Рахманинова - заключительная часть Un росо tranquillo. Этюд можно охарактеризовать как «смерть - погребальный звон (отзвуком чистой квинты звучащий тринадцать раз) - вознесение - прощание», что подчеркнуто фактурно, ладово, динамически. Неслучаен контраст минора и натурального мажора (как в панихиде после минорных «Со святыми упокой» и «Вечная память» - «Отче наш» и «Аллилуиа» в мажоре, претворяя «надгробное рыдание» в хвалебную песнь, 
как гимн вечной жизни во Христе). Три мажорных аккорда в заключении, сначала крещендирующие, а последний «затухающий», символизируют как бы уже «прощание в небесах».

Средства оркестровой имитации колокольности в финале «Колоколов»: «Здесь звон похоронный и он дается как фон для глубоко выразительной скорбной мелодии английского рожка. Таким образом, задание чисто изобразительного порядка сочетается тут с заданием раскрыть душевное состояние человека, охваченного мыслью о смерти, причем одно дополняет другое. Получается контрапункт двух планов, внешне выражаемый в сочетании акордово-фигуративных элементов у струнных, валторн и арфы (это - звон и в тоже время похоронный марш) с мелодией (английский рожок и солист-певец, как выразители душевного состояния)» [5, с. 113].

Выводы. Таким образом, многовековые традиции русского искусства, сохраняясь в «генетической памяти» культуры, возродились у русских композиторов рубежа XIX-XX веков, в идеях, образах, музыкальных интонациях. По мере удаления тех или иных событий и ухода очевидцев их, появляются искажения фактов, дат, и самой истории. Поэтому столь важна функция искусства, запечатлевающего эти факты, события в словах, красках, звуках, бережно сохраняющего их и передающего историческую правду потомкам. Говоря о сохранности «памяти культуры» не только в национальном, но и в общемировом масштабе, который является актом политическим, разрушающим попытки национальной вражды, снова обратимся к мудрым мыслям великого ученого XX века акад. Д.С. Лихачева, столь актуальным сегодня: «Культурный горизонт мира непрерывно расширяется... Глубокое проникновение в прошлое культуры своего и других народов сближает времена и страны. Единство мира становится все более и более ощутимым. Расстояния между культурами сокращаются, и все меньше остается места для национальной вражды и тупого шовинизма. Это величайшая заслуга гуманитарных наук и самих искусств - заслуга, которая в полной мере будет осознана только в будущем» [4, с. 29].

\section{СПИСОК ЛИТЕРАТУРЫ}

1. Альшванг А. П.И. Чайковский. Изд.2-е. Москва : Музыка, 1967. 927 c. 
2. Брянцева В. С.В. Рахманинов / В.Н. Брянцева. Москва : Советский композитор, 1976. 645 с.

3. Исаева И. О мелодической природе гармонии и фактуры Мусоргского / Вопросы теории музыки. Вып. 3. Ред.-составитель Т. Мюллер. Москва : Музыка, 1975. С. 132-157.

4. Лихачев Д. Великое наследие: Классические произведения литературы Древней Руси. Москва : Современник, 1980. 412 с.

5. Оркестр Рахманинова / Богатырев С. Исследования. Статьи. Воспоминания. Москва : Советский композитор. 1972. С. 99-114.

6. Осадчая С. Ключевые символы поминовения в композиторском творчестве. Муз. мистеитво і культура. Вып. 6. Кн. 2. Одесса, 2005. C. $49-54$.

7. Русская духовная музыка в документах и материалах. Том IV: Степан Васильевич Смоленский. Воспоминания: Казань-Москва-Петербург / Гос. центральный музей музыкальной культуры им. М.И. Глинки ; Подгот. т-та, вступит. ст. и коммент. Н.И. Кабановой; Науч. ред. М.П. Рахманова. Москва : Языки славянской культуры, 2002. 688 с. (Язык. Семиотика. Культура).

8. Ручьевская Е.А. Работы разных лет. Сб. статей в 2 т. / Т. II. О мвокальной музыке / Отв. Ред. В.В. Горячих. Санкт-Петербург : Композитор-Санкт-Петербург, 2011. 504 с., нот.

9. Сухомлинов И. Сухомлинов И. К проблеме интерпретации этюдов-картин Рахманинова. Мастерство музыканта-исполнителя. Москва : Советский композитор, 1976. Вып.2. С. 147-186.

10. Флоренский П. Иконостас. Москва, 2005. 204 с.

11. Экономцев Иоанн, игум. Православие. Византия. Россия. Сборник статей. Москва : Христианская литература, 1992. 230 с.

\section{REFERENCES}

1. Alshwang A. (1967). P.I. Tchaykovsky. Publicion 2. Moscow : Music. [in Russian].

2. Bryantzeva V. (1976) S.V. Rachmaninov. Moscow : Soviet composer. [in Russian].

3. Isayeva I. (1975). About melodic nature of harmony and facture of Musorgsky / The questions of theory of music. // editor-compiler T. Muller. Moscow : Music. [in Russian].

4. Lykhachev D. (1980). The Great Heritage: Classic works of literature of Ancient Rusi. Likhachev D. (1980). The great heritage: Classic works of literature of ancient Rusi. Moscow : Sovremennik. [in Russian].

5. The orchestra of Rachmaninov (1972) / Bogatyrev S. Researchings. Articles. Rememberings. M.: Soviet composer. [in Russian].

6. Osadchaya S. (2005) Key symbols of memory in composer art. Music art and culture. Issue 6. Book 2. Odessa. [in Russian]. Pp. 49-54.

7. Russian spiritual music in documents and materials. V. IV: Stepan Vasylievich Smolensky (2002). Rememberings: Kazan-Moscow-StPetersburg / St. central museum of music culture by M.I. Glynka; Prep. t., ent. art. and comments of N. Kabanova; Scien. edit. by M. Rachmanova. 
M.: The languiages of slav. culture (Languiage. Semiotic. Culture) [in Russian].

8. Ruchjevskaja E. (2011).The works of different years. Coll. of articles in 2 v. / T. II. About vocal music / V.V. Goryachikh (Ed.). SPg. : Composer Sanct-Petersburg. [in Russian].

9. Sukchomlinov I. (1976). To problem of interpretation of EtudesTableaux of Rachmaninov. Skill of musician-perfomer. Moscow : Soviet composer. Issue 2. [in Russian]. Pp. 147-186.

10. Florensky P. (2005) Ikonostas. Moscow. [in Russian].

11. Economtsev Ioann, (1992), igumen. Orthodox. Visantia. Russia. Coll. of articles. Moscow: "Christian literature". [in Russian].

УДК 782.1

DOI https://doi.org/10.31723/2524-0447-2020-30-2-15

Тетяна Петрівна Книшова

ORCID: 0000-0003-4699-5464

заслужена артистка України, доцент, приват-професор кафедри сольного співу

Одеської національної музичної академії імені А. В. Нежданової tatyana.knyshova@gmail.com

\section{ХРИСТИЯНСЬКІ АСПЕКТИ ПОЕТИКИ «БОРИСА ГОДУНОВА» М. МУСОРГСЬКОГО ТА ЇХ УТІЛЕННЯ В СЦЕНІЧНІЙ ВЕРСІЇ А. ТАРКОВСЬКОГО}

Мета роботи - виявлення християнського складника поетики «Бориса Годунова» М. Мусоргського й особливостей іï інтерпретаиіі в режкисерській постановочній версії А. Тарковського. Методологія дослідження спирається на інтонаційну концепцію музики, а також на міждисииллінарний та історико-культурологічний підходи, що дають змогу виявити духовно-релігійне підгрунтя музичного театру М. Мyсоргського, зокрема його опери «Борис Годунов». Наукова новизна роботи полягає в подальшому поглибленні та збагаченні уявлень про поетику оперної творчості М. Мусоргського й особливості ї̈ інтерпретації в умовах духовно-етичних шукань європейської культури кіния XX століття. Висновки. «Борис Годунов» М. Мусоргського являє собою унікальний твір європейського музичного театру ХІХ століття. Численні

(C) Книшова Т. П., 2020 